\title{
Using algorithmic design tools at the stage of building operation
}

\author{
Natalia Knyazeva ${ }^{1, *}$, and Daria Levina ${ }^{1}$ \\ ${ }^{1}$ Moscow State University of Civil Engineering, 26, Yaroslavskoe Shosse, 129337, Moscow, Russia
}

\begin{abstract}
Nowadays automation tools for separate construction processes and transmission of information model between different software frameworks are being developed. Prominent among these are plugins for nodes or visual programming, which are used to solve specific challenges. The procedures of solving them are considered to be possible variants for BIM-scenarios usage. The main goal of the study is demonstration of an example of using algorithmic design for the object operation stage. In this article we formulated and analyzed BIM-scenarios for the building operation stage at the building technical condition monitoring sub-stage and we offered to use tools for algorithmic design to automate implementation of processes of a considered scenario and also formed the main conclusions for the presented study.
\end{abstract}

\section{Introduction}

Digital transformation of the construction industry influenced the sphere of building and structures operation and maintenance, making companies come up with innovative solutions and automation tool to enhance security. Along with integrated usage of information modeling tools, organizations pay great attention to the development of specific plugins for automating mostly routine tasks.

Studies show that visual programming at the design stage is gaining popularity. This tool allows you to:

1. Create complex geometry, which would be difficult to implement without programming.

2. Develop parametric objects, which makes the created object almost universal.

3 . Control the created object by monitoring the programmed parameters.

According to the article [1], the existing practice of construction compliance is a costly bottleneck in a construction project, and that is why there is a need for project evaluation process, which includes automated capabilities to eliminate the inefficiencies and susceptibility to current manual verification practices.

This technology is a new paradigm in the field of design and programming, since its main means of work are graphic images of objects, parameters and the relationships between them. This tool opens up new opportunities for designers to automate the process of modeling complex geometry, analyze project data and statistics output. Data and their

\footnotetext{
*Corresponding author: nknyazeva@mgsu.ru
} 
processing algorithms are the basis of parametric design. The process of algorithmic design is extremely logical and requires a clear statement of the project design and the steps to achieve it.

Based on a reviewed literature on the topic under study, we can conclude that so far this technology is used mainly in architecture and design. Rhino - Grasshopper was used at Heatherwick Studio, a London-based design studio known for many large projects for private organizations and government companies, such as the London Routemaster doubledecker bus. Designers created a 3D model with the help of Rhino. There were also debates about the combination of digital design with manual work. Ceramic vases of complex mathematical form were created using this combination of Rhino - Grasshopper.

Parametric modeling, the use of curved lines to obtain a three-dimensional shape, is an intriguing starting point for the design of innovative flexible structures [2].

A striking example of the use of visual programming is the design of the Charles Perkins Center building, created by Fjmt. Architects managed to reproduce the design idea with the help of special techniques. The Grasshopper Life Connection extension allows you to organize data exchange in the Rhino-Grasshopper-ARCHICAD bundle. Some elements of the ARCHICAD BIM model can be created using conversion algorithms in Grasshopper.

This way of working provides an opportunity for the user to create not only a highquality parameterized picture, but also allows you to analyze the model, optimize any processes. For example, Stijn Brancart, Niels De Temmerman, Lars De Laet, O. PopovicLarsen in their work [3] give an example of an adaptive facade development. Adaptive architecture allows you to adjust some geometric characteristics taking into account environmental indicators: temperature, humidity, pressure. In the article mentioned above, a similar adaptive facade was developed for a four-storey building. The task was to change it, depending on the angle of incidence of the sun rays. The analysis was conducted at Archsim, the Energy Modeling plugin and DIVA at Rhino-Grasshopper in conjunction with the EnergyPlus simulation engine.

We would like to draw attention to the work in which the author is exploring the introduction of an automatic approach for efficient and reliable geo-referencing of BIM models in a GIS environment. Such example proves that algorithmic modeling starts to vary a lot [4].

The above examples of algorithmic design use relate to tasks that are solved at the stage of designing the construction project life cycle and there can be an unlimited number of such challenges. In the context of information modeling, such tasks, if necessary, are divided into final subtasks, which are called BIM scenarios. At the same time, it is necessary to divide the tasks into a sufficient number of BIM scenarios and use the quantity that will be appropriate at each stage of development. There are three stages:

The first stage is an overview map of the applied BIM scenarios: the main stages of activity are highlighted in the framework of achieving the goal, the responsible parties are picked out.

The second stage is the construction of a detailed map of the BIM scenarios processes: certain BIM scenarios are decomposed into processes, taking into account the interaction of the executors, and the conditions for performing specific procedures in the block diagram of each task.

The third stage is the development of information exchange: a description of input, output and intermediate information.

. In this work, we offer a classification of a possible set of BIM scenarios for the following task: "Monitoring the buildings technical condition".

The aim of this work is to analyze the applicability of algorithmic design as part of the operation stage of the construction project for the implementation of BIM-scenarios for monitoring building structures. 


\section{Materials and methods}

Customers are in need of more complicated automation solutions, on the one hand, and improved usability, on the other. The main task of creating such systems is to increase the time of trouble-free operation, safety and reduce the cost of administering the operation process. In this environment, it is not easy for service department specialists to learn new software systems to solve their problems at a qualitatively new level.

Sergey Ekba in his study points out that the creation and application of a BIM-model of existing buildings makes it possible to control and manage the systems of the object, which in turn allows us to provide the necessary safety parameters and standard operational performance of the building, as well as reduce the economic damage resulting from sudden accidents [5].

From the point of view of ensuring safety, the crucial step is the assessment of the technical condition of the building. Various diagnostic methods are used (laser scanning, ultrasonic meters, etc.) and all the results are reduced to an operational information model, on the basis of which a monitoring system is developed. The main parameter with which it is possible to evaluate the technical condition of the building is deformation. They use an indirect method of measuring information, based on the transformation of deformation into displacement, and then measuring this displacement.

Earlier we talked about possible options for classifying BIM scenarios during the operational stage. Particularly, we described 10-05-04-FRS - Monitoring the buildings technical condition. However, the Method of integration with the information model proposed in [6], namely, "Extracting information using the IFC format and placing it in the COBie format", is not the only one (Table 1). The method of exchange in the IFC format is analyzed in detail in [7] and the possibilities of this data format are considered

Table 1. BIM-scenario "Monitoring the buildings technical condition".

\begin{tabular}{|c|c|c|c|}
\hline Code & Description & Tool & Integration with information model \\
\hline $\begin{array}{c}\text { 10-05-04- } \\
\text { FRS }\end{array}$ & $\begin{array}{l}\text { Monitoring the } \\
\text { buildings } \\
\text { technical } \\
\text { condition }\end{array}$ & $\begin{array}{c}\text { ZETlab } \\
\text { Tool (sensor) } \\
\text { using which } \\
\text { we gather data }\end{array}$ & $\begin{array}{c}\text { Extracting information using IFC format and } \\
\text { placing it in COBie, extracting information } \\
\text { using algorithmic methods of visual } \\
\text { programming }\end{array}$ \\
\hline
\end{tabular}

Algorithmic design gives us great opportunities in data processing. Since the information environment has the function of self-improvement, the programs for processing data arrays and all processes modeling are also being improved.

One of the monitoring stages is the establishment of the observation site - the place for the sensor to be installed in accordance with GOST 32019-2012 Monitoring of the technical condition of unique buildings and structures. The design and stationary monitoring systems (stations) installation rules indicate the need for an analysis of structural features and the construction of a hazard identification model for a building. Due to the lack of a clear regulation in the domestic standards for the determination of such zones, the principle of monitoring the busiest sections and stress concentration sections is used.

In the combination Grasshopper - Sapphire or Grasshopper - SOFiSTiK, a parameterized finite element model is automatically generated with a maximum of data necessary for calculation (if the results of such calculations were not transferred from the design operating organization). At the same time, Grasshopper visual programming tools can identify places of dramatic changes in the geometric dimensions of constructions in the information model without resorting to using additional software and, with a certain algorithms adjustment, with the possibility of setting variable parameters without leaving 
the information modeling environment. In this case, it is possible to take into account the types and number of available sensors.

The results of the monitoring are collected in the specific database and subjected to mathematical analysis, on the basis of which the degree of risk of further operation of the building or structure as a whole is defined. It is also possible to present a visual display of the calculated data in an information modeling environment using pre-parameterized algorithms that describe the conditions for such visualization.

The Grasshopper - SOFiSTiK bundle is starting to become popular in the field of construction analysis.

It should also be pointed out that along with the Grasshopper - SOFiSTiK bundle, the Grasshopper - SAPPHIRE system is also used. Grasshopper has currently developed a plugin that provides a solution for transferring major geometric shapes into full-fledged BIM elements. The app allows you to create structural elements from the Grasshopper visual programming environment: beams, columns, walls. The tools of this plugin together with Grasshopper tools provide the formation of 3D models in the SAPPHIRE environment. Editing a model in Grasshopper or Rhinoceros leads to automatic regeneration of models in SAPPHIRE-3D. In this case, based on the results of the presented joint work of the systems, a parametrized calculation scheme is automatically generated with a maximum of data that is needed for a precise calculation.

\section{Results}

Each BIM scenario is a specific step in information modeling and their composition depends on the stage of work with the object, on the type of work with information and on the tool that is used to obtain this information. In this specific example, we consider a BIM scenario with the code 10-05-04-FRS, which is detailed in accordance with the task. Thus, going down to the second more detailed stage of developing BIM-scenarios, we can offer the following set and classification as an example (Table 2).

Table 2. BIM-scenarios of the operation stage of the sub-stage Monitoring the unique buildings and structures technical condition.

\begin{tabular}{|c|c|c|c|}
\hline Code & Description & $\begin{array}{c}\text { Tool, } \\
\text { operation }\end{array}$ & $\begin{array}{c}\text { Interaction, integration with the information } \\
\text { model }\end{array}$ \\
\hline $\begin{array}{c}10-22-03- \\
\text { FRS }\end{array}$ & $\begin{array}{c}\text { Selecting zones } \\
\text { to install sensors }\end{array}$ & $\begin{array}{c}\text { Visual } \\
\text { inspection and } \\
\text { analysis }\end{array}$ & - \\
\hline $\begin{array}{c}\text { 10-01- } \\
\text { FRS }\end{array}$ & $\begin{array}{c}\text { Consideration of } \\
\text { the types and } \\
\text { quantities of } \\
\text { equipment } \\
\text { available }\end{array}$ & $\begin{array}{c}\text { MS Excel } \\
\text { MS Access }\end{array}$ & $\begin{array}{c}\text { Collecting data in ACCDB, MDB, XLSX, } \\
\text { XML formats }\end{array}$ \\
\hline $\begin{array}{c}\text { 10-01-13- } \\
\text { FRS } \\
\text { processing } \\
\text { monitoring } \\
\text { results }\end{array}$ & $\begin{array}{c}\text { Dasher 360, } \\
\text { Grasshopper- } \\
\text { SOFiSTiK }\end{array}$ & $\begin{array}{c}\text { IM import into Rhino-Grasshopper } \\
\text { environment is possible }\end{array}$ \\
\hline $\begin{array}{c}\text { 10-03-33- } \\
41 \text { FRS }\end{array}$ & $\begin{array}{c}\text { Categorization } \\
\text { and visualization } \\
\text { of the results }\end{array}$ & $\begin{array}{c}\text { Grasshopper }- \\
\text { SOFiSTiK }\end{array}$ & $\begin{array}{c}\text { IM import into Rhino-Grasshopper } \\
\text { environment is possible }\end{array}$ \\
\hline
\end{tabular}

Due to a detailed consideration of the BIM scenario under the code 10-05-04-FRS, it becomes necessary to expand the list of possible operations at the operational stage. The following types of work with information as it was done in this article [6] were added to the 
encoding. These operations are necessary for the implementation of the corresponding steps presented in the "Description" column:

13. Monitor - collecting information (observation) about elements work and object systems.

22. Arrange - coordinates tracking and placing object elements.

33. Validate - verification, confirmation of the information accuracy of the object.

41. Visualize - the formation of a realistic view of the object and its elements.

In scenario 10-22-03-FRS, it is essential to determine the location of the sensors and their quantity. These indicators may vary depending on the operating construction, the construction under consideration or the construction element. The code 22 at the stage of operation may indicate the determination of the coordinates of the sensors. It is also necessary to analyze the most vulnerable points of the construction.

"Consideration of the types and quantities of equipment available" - the next step is to make a decision on the quantity of sensors to be placed after analysis, visual inspection of the building.

At the stage of "Obtaining and processing monitoring results", specialists need to structure the obtained data from sensors localized at the construction. At this step, it is important not only to collect, but to stably control the indicators, that is, the construction efficiency, its deformation.

In the last scenario 10-03-33-41, a complete visualization of the data obtained in the digital model environment is reflected, for example Grasshopper - SOFiSTiK or Grasshopper - SAPPHIRE.

\section{Discussions}

This study was conducted to demonstrate the efficiency of the use BIM scenarios to monitor constructions using algorithmic design systems in the context of the construction project operation stage. The possible list of BIM scenarios was presented in the work.

1. Selecting zones to install sensors.

2. Consideration of types and quantity of the equipment available.

3. Obtaining and processing monitoring results.

4. Categorization and visualization of the results.

We would like to note that this list is not the only and complete one. It may depend on the type of task, on the object under study, on the requirements of the operating organization.

Also, in this work, we considered one of the least studied from the point of view of using information modeling tools stages of the life cycle of a construction - its operation, or rather the process "Monitoring the buildings technical condition" and suggested an automation method using Grasshopper - SOFiSTiK, which allows operating services:

1. Automate the process of identifying the most hazardous areas of a structure.

2. Do not resort to the use of additional software systems.

\section{Conclusion}

Regarding the analysis of the possibility of using node programming for the implementation of the BIM scenario, Monitoring of the technical condition of unique buildings and structures, the following conclusions were drawn:

- for an accurate study of the model or the formation of information, it is necessary to develop a regulatory framework governing the composition of BIM scenarios; 
- to use the digital model during the operation stage, it is necessary to determine the most rational format of the model for integration with other software systems;

- scripts developed for operational tasks can be universal and reused for standard objects or its elements.

\section{References}

1. P. Ghannad, Y.-Ch. Lee, J. Dimyad, W. Solihinc, Advanced Engineering Informatics, 40, 14-28 (2019) DOI: 10.1016/j.aei.2019.01.006

2. A. Vergauwen, L. De Laet, N. DeTemmerman, Computer-Aided Design, 83, 51-63 (2017) DOI: 10.1016/j.cad.2016.10.002

3. S. Brancart, N. De Temmerman, L. De Laet, O. Popovic-Larsen, Structures and Architecture - Bridging the Gap and Crossing Borders, 1 (2019)

DOI:10.1201/9781315229126-26

4. S. Zlatanova, Computers, Environment and Urban Systems, 80, 101453 (2020) DOI: 10.1016/j.compenvurbsys.2019.101453

5. S. Ekba, E3S Web of Conferences, 110, 01081 (2019) DOI:

10.1051/e3sconf/201911001081

6. N. Knyazeva, D. Levina, , E3S Web of Conferences, 91, 08026 (2019) DOI: 10.1051/e3sconf /20199108026

7. Sh. Tang, D.R. Shelden, Ch.M. Eastman, P. Pishdad-Bozorgi, X. Gao, Automation in Construction, 110, 103049 (2020) DOI: 10.1016/j.autcon.2019.103049 